\title{
Using PPG Segmentation Analysis, Waveform Characteristics Analysis and Energy Theory to Investigate the Linkage among Brain, Liver, and Gastrointestinal System (GH-Method: Math-physical Medicine)
}

Gerald C. Hsu

EclaireMD Foundation, USA

\section{Introduction}

In this paper, the author analyzed his 1,708 meals that are segregated into 26 different segments. The purpose is to attempt the validation of his hypothesis on the relationship from the directive of the brain to the gastrointestinal functions and liver's glucose production capability.

\section{Methods}

The author used a continuous glucose monitoring device (Sensor) applied to his upper left arm. He has collected $\sim 74$ glucose data each day since 5/5/2018. In this particular analysis, he selected the entire Sensor period of 549 days $(5 / 5 / 2018$ - 11/4/2019) with 40,626 total glucose data, 1,706 PPG waveforms, and 20,472 PPG Sensor data (12 data per meal).

\section{Results}

Figure 1 lists glucose data in a calculation table of six low-carbs and high-protein meals and three standard meals, i.e. breakfast, lunch, and dinner.

\begin{tabular}{|c|c|c|c|c|c|c|c|c|c|c|c|c|c|c|c|}
\hline$(5 / 5 / 2018-11 / 4 / 2019)$ & Meals 배 & Meals $\%$ & Open PPG & OpenX: & Peak PPG & Peak\% & $120 \mathrm{~m}$ PPG & $120 \mathrm{mx}$ & $180 \mathrm{~m}$ PPG & $180 \mathrm{mX}$ & Avg & Energy & Carbs (g) & Drop (p-120) & Fnger \\
\hline Breakfast with egg only & 39 & $2 \%$ & 127 & $98 \%$ & 153 & $105 \%$ & 135 & $100 \%$ & 131 & $100 \%$ & 138 & $103 \%$ & 7.4 & 18 & 114 \\
\hline Meal with Cheese only & 33 & $2 \%$ & 127 & $99 \%$ & 142 & $98 \%$ & 132 & $98 \times$ & 127 & $97 \%$ & 133 & $95 \%$ & 7.0 & 10 & 111 \\
\hline Meal with Sashimi only & 32 & $2 \%$ & 131 & $101 \%$ & 130 & $89 \%$ & 110 & $82 \%$ & 118 & 9006 & 119 & $77 x$ & 4.8 & 20 & 104 \\
\hline Meal with esg and others & 348 & $20 \%$ & 128 & $99 \%$ & 145 & $100 \%$ & 132 & $98 \%$ & 130 & $99 \%$ & 135 & $97 \%$ & 8.7 & 13 & 112 \\
\hline Meal with 5 high-protein & 663 & $39 \%$ & 126 & $98 \%$ & 145 & $100 \%$ & 132 & $98 \%$ & 130 & $99 \%$ & 134 & $97 \%$ & 8.7 & 13 & 114 \\
\hline (5/5/2018 - 11/4/2019) & Meals ㅂ. & Meals $\%$ & Open PPG & Openx & Peak PPG & Peak* & $120 \mathrm{~m}$ PPG & $120 \mathrm{~ms}$ & $180 \mathrm{~m}$ PPG & $180 \mathrm{~m} \times$ & Avg & Energy & Carbs (g) & Drop (P-120) & Fnger \\
\hline Lunch with All kinds & 547 & $32 \%$ & 135 & $104 \%$ & 149 & $103 \%$ & 139 & $104 \%$ & 133 & $101 \%$ & 140 & $106 \%$ & 16.1 & 10 & 117 \\
\hline Dinner with All kinds & 542 & $32 \%$ & 130 & $101 \%$ & 139 & $95 \%$ & 127 & $94 \%$ & 127 & $97 \%$ & 131 & $92 \%$ & 15.1 & 12 & 112 \\
\hline All Meals & 1708 & $100 \%$ & 129 & $100 \%$ & 145 & $100 \%$ & 134 & $100 \%$ & 131 & $100 \%$ & 136 & $100 \%$ & 14.4 & 11 & 116 \\
\hline
\end{tabular}

Figure 1: Six low-carb and high-protein meals with three standard meals

"Correspondence author

Gerald C. Hsu

EclaireMD Foundation

USA

Submitted : 16 May 2020 ; Published : 30 May 2020

Each standard PPG waveform has an "open" glucose (0 minute, i.e. at first bite of meal), "peak" glucose (usually around 60-minutes), "120-minutes" glucose (close to Finger PPG measurement time), and "180-minutes" glucose. He also calculated the "averaged" Sensor PPG data over three hours and their associated energy which circulates within the blood flow in blood vessels reaching to every part of the internal organs, except hair. In addition, each meal's carbs/sugar intake amounts are also measured and recorded. The main purposes of this study is to attempt the validation of his existing and instinctive belief for six months, since the beginning of May of 2019, after collecting Sensor data for one year. 
Figure 2 displays glucose data in a calculation table of five different eating places and six nations.

\begin{tabular}{|c|c|c|c|c|c|c|c|c|c|c|c|c|c|c|c|}
\hline$(5 / 5 / 2018$ 11/4/2019) & Meals \#| & Meals X & Open PPG & Openx & Peak PPG & Peakx & $120 \mathrm{~m}$ PPG & $120 \mathrm{~m} \times$ & $180 \mathrm{~m}$ PPG & $180 \mathrm{mK}$ & Avg & Energy & Carbs (s) & Drop (P-120) & Fnger \\
\hline Home Cook & 805 & $47 \%$ & 132 & $102 \%$ & 143 & $98 \%$ & 127 & $94 \%$ & 123 & $94 \%$ & 132 & $94 \%$ & 10.9 & 16 & 111 \\
\hline Chain Restaurant & 274 & $16 \mathrm{~K}$ & 124 & $96 \%$ & 149 & $102 \%$ & 137 & $102 \%$ & 135 & $103 \%$ & 137 & $102 \%$ & 11.8 & 12 & 118 \\
\hline Indlwidual Restaurant & 459 & $27 \%$ & 129 & $100 x$ & 148 & $102 \%$ & 143 & $106 \%$ & 140 & $107 \%$ & 141 & $107 \%$ & 20.7 & 5 & 122 \\
\hline Airline & 73 & $4 \%$ & 132 & $103 \%$ & 149 & $102 \%$ & 145 & $108 \%$ & 138 & $105 \%$ & 143 & $109 \%$ & 20.9 & 4 & 126 \\
\hline Supermarket & 31 & 256 & 136 & $105 \%$ & 171 & $117 \mathrm{x}$ & 163 & $121 \%$ & 138 & $105 \%$ & 155 & $129 \%$ & 23.4 & 8 & 124 \\
\hline All Meals & 1708 & $100 \%$ & 129 & $100 \%$ & 145 & $100 \%$ & 135 & $100 \%$ & 131 & $100 \%$ & 136 & $100 \%$ & 14.4 & 11 & 116 \\
\hline Tahwan & 291 & 178 & 128 & $99 \%$ & 143 & $95 \%$ & 127 & $95 \%$ & 127 & $97 \%$ & 132 & $93 \%$ & 20.4 & 16 & 121 \\
\hline Japan & 155 & $9 \pi$ & 129 & $100 x$ & 141 & $97 \%$ & 136 & $101 \%$ & 131 & $100 x$ & 136 & $99 \%$ & 23.5 & 5 & 124 \\
\hline USA & 904 & $53 \%$ & 130 & $101 \%$ & 146 & $100 x$ & 132 & $98 \%$ & 131 & $100 \%$ & 136 & $100 x$ & 12.2 & 14 & 114 \\
\hline Other Nations & 222 & $13 \times 6$ & 124 & $96 \%$ & 147 & 1018 & 144 & \begin{tabular}{|l|}
$107 \%$ \\
\end{tabular} & 136 & $104 \%$ & 140 & $105 \mathrm{x}$ & 18.6 & 3 & 120 \\
\hline Airlines & 73 & 45 & 132 & $103 \%$ & 149 & $102 \%$ & 145 & $108 \%$ & 138 & $105 \%$ & 143 & 109\% & 20.9 & 4 & 126 \\
\hline Canada & 16 & $1 \%$ & 132 & $102 \%$ & 165 & $113 \mathrm{x}$ & 157 & $117 \%$ & 156 & $119 \%$ & 154 & $127 \%$ & 21.9 & 8 & 118 \\
\hline All Meals & 1708 & $100 \%$ & 129 & $100 \%$ & 145 & $100 \%$ & 135 & $100 \%$ & 131 & $100 \%$ & 136 & $100 \%$ & 14.4 & 11 & 116 \\
\hline
\end{tabular}

Figure 2: Five eating places and six nations

Figure 3 shows glucose data in a calculation table of two low-carbs meals and four high-carbs meals according to the difference range of carbs/sugar intake amount.

\begin{tabular}{|c|c|c|c|c|c|c|c|c|c|c|c|c|c|c|c|}
\hline (S/S/2018 - 11/4/2019) & Meals \# & Meals \% & Open PPG & Openx & Peak PPG & PeakX & $120 \mathrm{~m}$ PPG & $120 \mathrm{mx}$ & $180 \mathrm{~m} P \mathrm{PPG}$ & $180 \mathrm{~m} \times$ & Avg & Energy & Carbs (R) & Drop (P-120) & Fnger \\
\hline Low carbs (0.5 gram) & 248 & $15 \%$ & 127 & $99 \%$ & 136 & $93 \%$ & 125 & $93 \times$ & 129 & $98 \times$ & 129 & $90 \%$ & 2.2 & 10 & 110 \\
\hline Low carbs (0-10 gram) & 757 & $44 \%$ & 128 & $99 \%$ & 139 & $95 \%$ & 125 & $93 \%$ & 126 & $96 \%$ & 130 & $91 \%$ & 6.4 & 14 & 109 \\
\hline Low carbs (0-14.9 gram) & 1134 & $66 \%$ & 128 & $99 \%$ & 140 & $97 \times$ & 128 & $95 \%$ & 127 & $97 \pi$ & 132 & $93 \%$ & 8.5 & 12 & 111 \\
\hline High-carbs (15-20 gram) & 297 & 1778 & 131 & $101 \%$ & 151 & $103 x$ & 140 & $104 \%$ & 132 & 1018 & 140 & $106 \%$ & 17.7 & 11 & 118 \\
\hline High-carbs (15-30 gram) & 449 & $26 \mathrm{~K}$ & 131 & $101 \%$ & 153 & $105 \%$ & 142 & $106 \%$ & 136 & $103 \%$ & 142 & $109 \%$ & 20.4 & 11 & 121 \\
\hline Hilgh-carbs (15-50 gram) & 541 & $32 \%$ & 131 & $101 \%$ & 154 & $106 x$ & 147 & $109 x$ & 139 & $106 \%$ & 145 & $113 \%$ & 23.6 & 8 & 124 \\
\hline Hilgh-carbs (15-100 gram) & 570 & 338 & 131 & $101 \%$ & 156 & $107 \%$ & 147 & $109 \%$ & 140 & $106 \%$ & 146 & $114 \times$ & 26.2 & 9 & 125 \\
\hline Hileh-carbs (15-150 gram) & 573 & 348 & 131 & 1015 & 156 & $107 \%$ & 148 & $110 \%$ & 140 & $107 \%$ & 146 & \begin{tabular}{|l|}
$115 \%$ \\
\end{tabular} & 26.8 & 8 & 126 \\
\hline All Meals (0-150 gram) & 1708 & $100 \%$ & 129 & $100 \%$ & 145 & $100 \%$ & 135 & $100 \%$ & 131 & $100 \%$ & 136 & $100 \%$ & 14.4 & 11 & 116 \\
\hline
\end{tabular}

Figure 3: Two low-carb meals and four high-carb meals

Figure 4 combines the above three separated tables together.

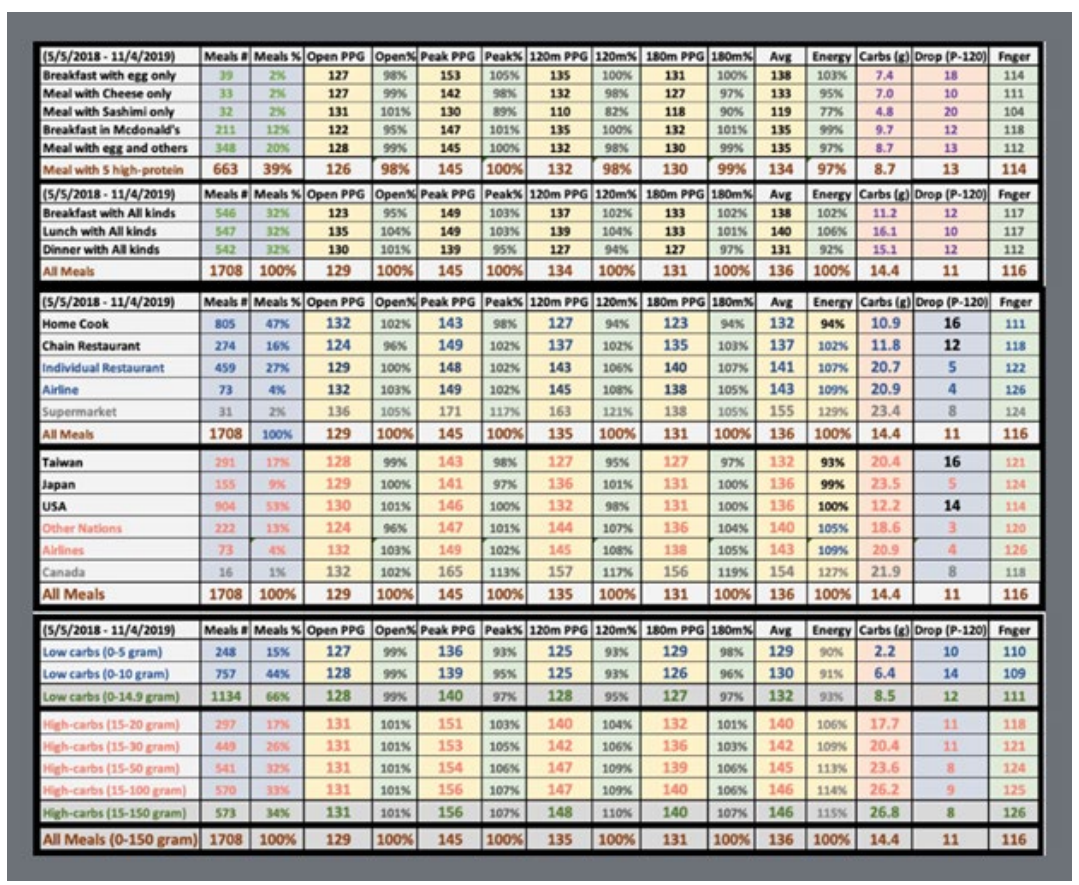

Figure 4: Total of 26 glucose segmentation analysis results

(Combination of Figures 1, 2, 3) 
The author will focus solely on the purpose of this paper and will omit many detailed information and some non-related items.
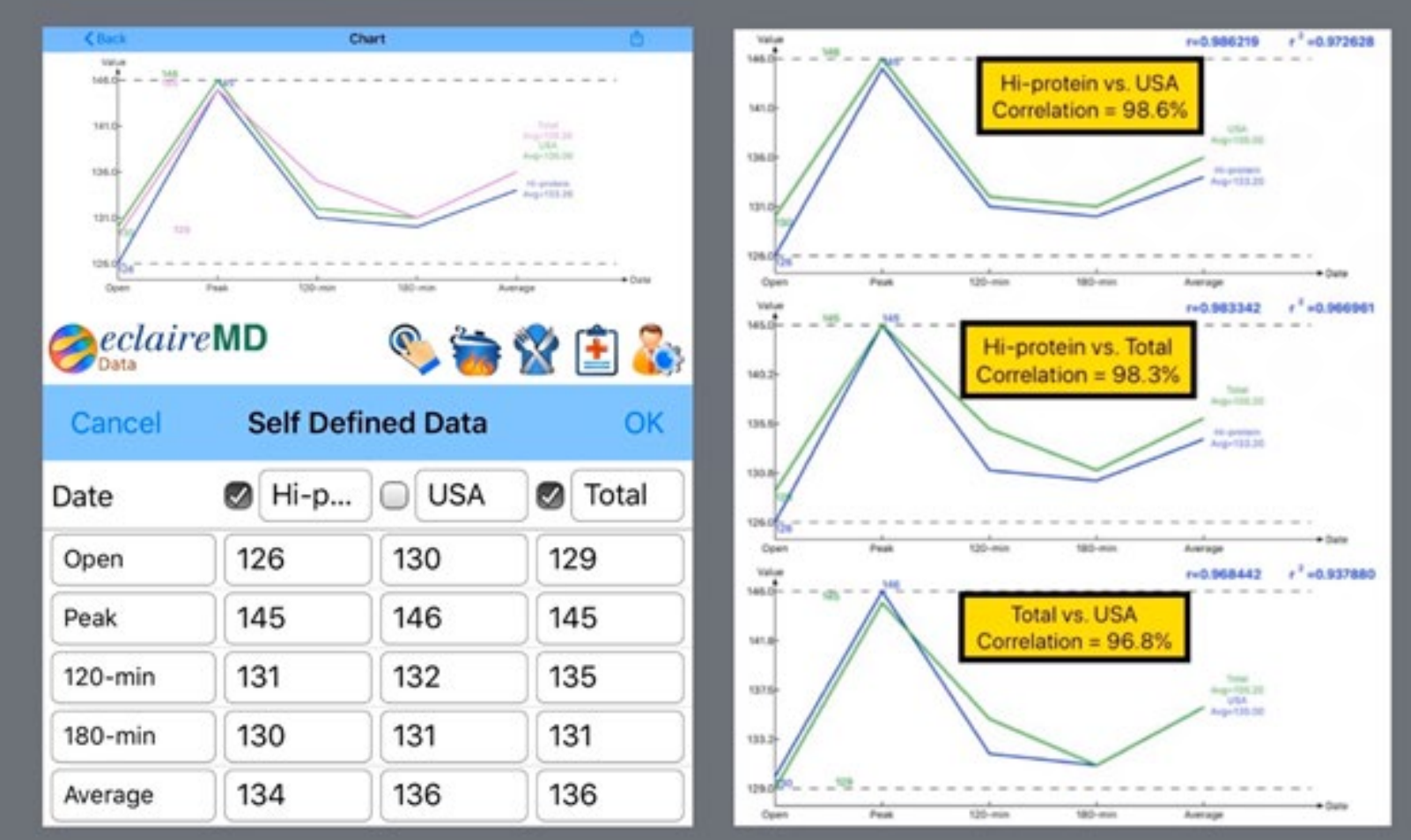

Figure 5: Quantitative and graphic interpretation of relationship between brain's order and liver's glucose production

The following paragraphs are based on Figures 4 and 5. Figure 5 is derived from Figure 4 and depicts those low-carbs meals, including both high-protein synthesized meal and U.S. meals (this is the most representative segment). It also compares with the total averaged glucose curve. The results show three very high correlation coefficients of $96.8 \%, 98.3 \%$, and $98.6 \%$.

At the peak glucose column, the overall peak glucose is 145 $\mathrm{mg} / \mathrm{dL}$ with around $2 \%$ to $3 \%$ deviation. The low-carb meals tend to be at $141 \mathrm{mg} / \mathrm{dL}$ to $143 \mathrm{mg} / \mathrm{dL}$ and high-carb meals tend to be around $149 \mathrm{mg} / \mathrm{dL}$ to $152 \mathrm{mg} / \mathrm{dL}$. This fact has proven his hypothesis that during the first hour after the first bite of food, the brain receives a "food-entry" signal from the gastrointestinal system and then almost immediately orders the liver to start glucose production. The small deviation of $4 \mathrm{mg} /$ $\mathrm{dL}$ to $5 \mathrm{mg} / \mathrm{dL}$ ( $3 \%$ to $4 \%$ ) may be due to carbs/sugar intake amount and exercise within the first hour.

However, the glucose at 120 minutes after the first bite of food (also close to conventionally recommended finger measurement time) is a different story. During the 60-minutes peak time to 120 -minutes after eating a low-carb meal, the glucose reduces at an amount of $14 \mathrm{mg} / \mathrm{dL}$ ( $\sim 10 \%$ drop in one hour). However, when eating other high-carb meals, PPG decreases only around $3 \mathrm{mg} / \mathrm{dL}$ to $8 \mathrm{mg} / \mathrm{dL}$ with an average of $5.5 \mathrm{mg} / \mathrm{dL}$ ( $\sim 4 \%$ drop in one hour). This fact proves the high-carb food entry plays a vital role during the second hour. It cannot be "consumed" fast enough or completely; therefore, it creates an excessive left-over energy associated with these "unburned" glucoses circulating in the body within the blood flow.

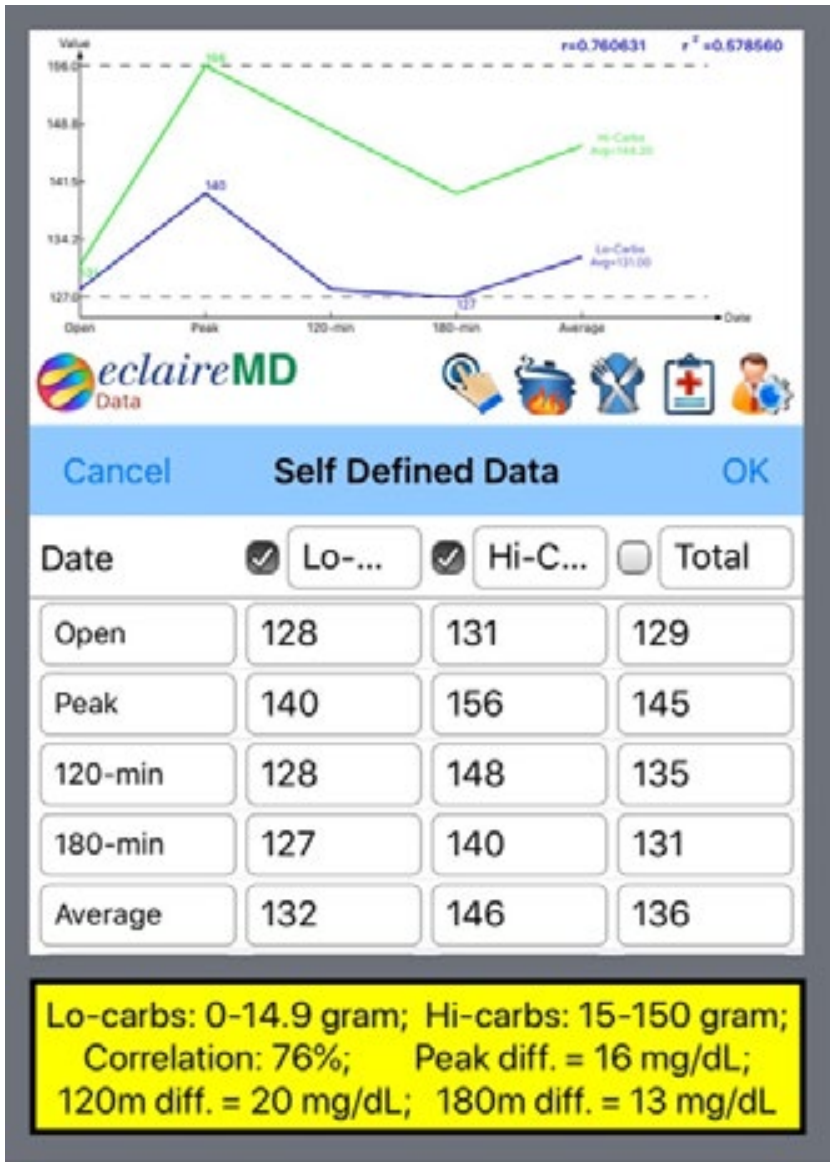

Figure 6: Comparison between low-carb meals vs. high-carb meals 
The above two paragraphs and Figures 5 and 6 have actually described the author's simulation model of the cycle from the brain via stomach to liver. Food still serves as the initial stimulator from the directive of the brain to issue the start of glucose production, while carbs/sugar intake and post-meal exercise serve as two follow-on stimulators as well as two major components of the glucose simulation model.

\section{Conclusion}

This paper further enhanced the author's previous papers regarding the brain neuroscientific function on glucose production. However, it describes the glucose physical behaviors in detail and phenomena with quantitative proofs during two separated time spans of the first hour and second hour after eating [1-4].

\section{References}

1. Hsu, Gerald C (2018) Using Math-Physical Medicine to Control T2D via Metabolism Monitoring and Glucose Predictions. Journal of Endocrinology and Diabetes 1(1): 1-6.

2. Hsu, Gerald C (2018) Using Signal Processing Techniques to Predict PPG for T2D. International Journal of Diabetes \& Metabolic Disorders 3(2): 1-3.

3. Hsu, Gerald C (2018) Using Math-Physical Medicine and Artificial Intelligence Technology to Manage Lifestyle and Control Metabolic Conditions of T2D. International Journal of Diabetes \& Its Complications 2(3): 1-7.

4. Hsu, Gerald C (2018) Using Math-Physical Medicine to Analyze Metabolism and Improve Health Conditions. Video presented at the meeting of the 3rd International Conference on Endocrinology and Metabolic Syndrome 2018, Amsterdam, Netherlands.

Copyright: (O2020 Gerald C. Hsu. This is an open-access article distributed under the terms of the Creative Commons Attribution License, which permits unrestricted use, distribution, and reproduction in any medium, provided the original author and source are credited. 